\title{
EL BOBO ILUSTRADO O EL INDIVIDUO AGREDIDO
}

Diego Fernández Sosa

I.E.S. "Valle de Ambroz" huella_sonora33@hotmail.com

\section{RESUMEN}

En este artículo se analizan las relaciones que establece Pedro de Vergara, protagonista de El bobo ilustrado, de José Antonio Gabriel y Galán, con su contexto histórico, espiritual y personal, basándonos específicamente en el espacio novelesco (el Madrid de julio de 1808), en las figuras femeninas que constituyen el universo imaginario del protagonista y, finalmente, en su actitud política ante la invasión napoleónica.

PAlABRAS ClaVe: Gabriel y Galán. Bobo ilustrado.

\section{ABSTRACT}

In this article, the relationship between Pedro De Vergara - the main character in El bobo ilustrado - and José Antonio Gabriel y Galán is analysed within its historical, spiritual and personal context, basing it specifically on the fictional background (Madrid, July 1808), the female figures which make up the main character's imaginary universe and, finally, on the attitude he took on the political context of the invasion by Napoleon.

KEY WORDS: Gabriel y Galán. Bobo ilustrado.

\section{INTRODUCCIÓN}

El análisis del individuo en El bobo ilustrado ${ }^{1}$ está configurado en virtud de tres aspectos o tres grandes líneas de desarrollo. En primer lugar, la relación entre el individuo y la ciudad; es decir, la forma en que el ambiente urbano y sus matices específicos influyen directamente

1 La edición que se ha manejado para el presente artículo es la de bolsillo de Alfaguara (1993). 
en el espíritu del protagonista y, además, son reflejo de ese mismo espíritu, al modo como el paisaje de los escritores del 98 se constituía como una transustanciación del alma del autor. A este respecto, en la breve revisión histórica de M. ${ }^{a}$ del Carmen Pena (1998:13-21) en torno al paisaje pictórico desde la cultura clásica grecolatina hasta el siglo XIX, la autora nos recuerda que «Con el Romanticismo el género del paisaje adquirió una alta consideración que hasta entonces no había tenido, expresándose dentro de las tendencias idealistas en forma poética o fantástica (Pena, 1998:17). Más adelante indica, conforme a la misma idea, que «El paisaje como expresión de ideas o sentimientos fue una constante a lo largo de todo el siglo XIX en artistas críticos, que veían reflejado en él al individuo, bien como sujeto histórico, bien como ser único» (Pena, 1998:19). En este sentido, se demostrará que ambas instancias -individuo y espacio urbano - quedan unidas por un vínculo de envilecimiento y deturpación que afecta paralelamente a uno y otro de forma sincronizada, mediante una colaboración simbiótica de destrucción sobre el protagonista Pedro de Vergara.

En segundo lugar, el análisis se lleva a cabo teniendo en cuenta el vínculo que establece el individuo con las tres figuras femeninas, específicamente con dos de ellas: Rahel Levin y Mariblanca, la sirvienta muda. En este caso, la exégesis intenta demostrar la polaridad de un mundo personal que se extiende entre los conceptos cernudianos de la realidad y el deseo, pero en el que participa también muy significativamente el valor de la libertad individual. Es cierto que el tema es cernudiano, pero ya Lukács (1971) apuntó originalmente el conflicto; en realidad se trata de un tema eterno, tal y como comenta Darío Villanueva al hablar de Extramuros, de Jesús Fernández Santos, en el sentido de que esta novela aborda «la falta de armonía entre la realidad y el héroe, que quisiera poseer un mundo de pasiones afirmativas y se encuentra en perpetua agonía en otro precario y deficiente» (Villanueva, 1979:44).

Y, por último, las particularidades del contexto histórico, polarizado del mismo modo en dos universos ideológicos contrapuestos, nos aporta otra faceta no menos importante del individuo de actitud irresoluta, pasiva y pusilánime que se sitúa en medio de tal dicotomía, sin capacidad para actuar expeditivamente en un sentido u otro.

Todos estos aspectos contribuyen a la idea de que las vidas humanas se configuran, en rigor, como una antítesis constante entre la realidad y el deseo, conflicto que conduce necesariamente a la alienación individual y, en última instancia, la destrucción (moral y física) del individuo. En cuanto al concepto de alienación, Gurméndez hace notar los muy diferentes sentidos de este término según el contexto cultural de que tratemos («operación comercial ventajosa», en inglés, o, en alemán, «trabajo serio, profundo, el despliegue o desarrollo de las más íntimas posibilidades de la individualidad» [Gurméndez, 1989:12]). El sentido que aquí utilizamos se refiere, obviamente, al español. En este caso, Gurméndez señala que «Esta palabra, alienación, es una variante culta de enajenar que deriva de ajeno, procedente del latín alienus y, a su vez, de alius que significa "otro" (...). Pero de los múltiples sentidos que tiene, en español, esta palabra, predomina la idea de Otro, bien sea para dar una cosa que es de uno, hacerse otro en la locura o ser extraño a uno mismo. En español, pues, la palabra alienación expresa la realidad del Yo como "ajeno" u "otro"» (Gurméndez, 1989:12).

No obstante, el punto de vista del autor de El bobo ilustrado difiere en cierto sentido de esta idea, al afirmar que uno de los rasgos comunes a los personajes de sus novelas es: «Su vulnerabilidad, el sentimiento de fragilidad que les impide entregarse al exterior, a la vida 
social, el sentimiento de acoso que les hace buscar refugio en su propia interioridad real o fantástica» (Gabriel y Galán, 1990:81). Juicio que amplía al establecer que: «Los personajes centrales de mis novelas (...) viven el mundo, efectivamente, como una hostilidad, y a partir de ahí se produce un conjunto de reacciones: desde el que vuelca la hostilidad hacia sí mismo hasta aquel al que la «tormenta» desbarata su propia identidad, pasando por el que huye, el que se esconde en su interior o el que se inventa un refugio fantástico» (Gabriel y Galán, 1990:81).

En efecto, la situación vital a la que se ve abocado Pedro de Vergara tiene su origen en los mencionados sentimientos de vulnerabilidad, fragilidad y acoso (todos ellos enraizados en unas premisas históricas muy determinadas), a los cuales el individuo va a responder, en este caso, mediante el recurso de la fantasía. La cual resulta ser una forma específica de deseo que se elabora como contestación a una realidad que lo acosa, lo vulnera, lo hace sentirse frágil y cuyos principios no comparte. De la disociación profunda entre los dos ámbitos, de su incesante conflicto, no puede surgir otra cosa que la destrucción o el exterminio del ser humano.

\section{EL INDIVIDUO Y LA CIUDAD: EL CRONOTOPO URBANO COMO EXTENSIÓN DEL ESPÍRITU}

Un primer contexto semiótico en la relación individuo-alma-espacio queda establecido por la visión que Vergara nos ofrece de la plaza de los Mostenses, la cual actualiza (aparte de aportar nociones estrictamente objetivas, históricas o intrahistóricas) el estado interior del individuo que lo contempla y describe desde una segunda voz narrativa, al modo de la corriente de conciencia joyceana.

Se puede aducir que, desde un punto de vista metafórico o alegórico, los acontecimientos históricos que van a ser referidos por el periodista de la Gazeta, así como la atmósfera de la plaza de los Mostenses, y otros ámbitos urbanos que se irán mostrando en el desarrollo de la narración, son paralelos (es decir, son consecuencia y corolario) al estado espiritual del propio individuo que los contempla. La relación entre los espacios urbanos y la degradación moral (y también física) del periodista afrancesado se percibe de modo más intenso hacia el final de la novela, a partir del episodio de los jumentos y el yeso y de la búsqueda de su compañero de redacción Francisco Rodríguez.

Efectivamente, la plaza aparece «encerrada entre conventos» (Gabriel y Galán, 1993:13) y «recogida sobre sí misma, protegiendo un silencio con el que podías toparte en cada esquina» (Gabriel y Galán, 1993:13). El ámbito, compuesto por figuras humanas y por los distintos matices del espacio exterior que vislumbra el periodista de la Gazeta desde su balcón, refleja la «situación confusa» (Gabriel y Galán, 1993:13) de la ciudad de Madrid en los primeros días de julio de 1808. Las expresiones aludidas representan instancias sutiles del alma de Pedro de Vergara ${ }^{2}$, un hombre en cierta forma encerrado y recogido en sí mismo y en medio de una situación histórico-política que repercute inevitablemente sobre su vida.

${ }^{2}$ La relación ciudad e individuo se intensifica, además, en no pocos momentos de la novela y, en este sentido, la presencia del cadáver del perro en descomposición no es casual; la mención de este elemento a lo largo de la narración va configurando una forma de hito espiritual reiterativo que se propone en último término como preaviso del final trágico del protagonista. 
Puede conjeturarse que el recogimiento, el encierro y el silencio del lugar anticipan el deseo implícito que más adelante expresa Pedro de Vergara con respecto al alejamiento físico (y no sólo físico, como se verá después) de su mujer, próxima a marcharse de Madrid (Gabriel y Galán, 1993:15); pero, en un sentido más transcendente, la atmósfera que se nos describe de la plaza, a modo de un cuadro de la época negra de Goya, trasluce un estado anímico del propio individuo, que se nos irá desvelando a medida que la narración avanza.

Sin embargo, en medio de este ámbito, lo que destaca significativamente es el cadáver en descomposición de un perro, símbolo inequívoco, asimismo, del momento histórico que se vive. Las alusiones al cadáver del perro aparecen referidas significativamente como un contrapunteo en tres lugares de la narración, en los capítulos XII, XXV, y XXVII (páginas 114, 222 y 244 respectivamente). El simbolismo del perro, desde el Cancerbero de la mitología grecorromana, es vasto; no obstante, conviene recordar la función de «guía del hombre en la noche de la muerte» (apud Chevalier, 2007:816) por la relación evidente de este animal con el destino trágico de Pedro de Vergara: «La imagen del perro muerto [...] aparecía familiar a los habitantes de aquellos alrededores. Nadie se había preocupado de llevárselo, ni siquiera la servidumbre del conde» (Gabriel y Galán, 1993:13).

Este cuadro externo contextualiza, por tanto, el ámbito familiar del Pedro de Vergara, en vías — como el animal muerto— de descomposición por la marcha de su mujer y su hijo a tenor de las turbulencias políticas. El cuadro de la ciudad que empieza a iluminarse se amplía con la narración del inicio del alumbrado público: «En la plaza de los Mostenses se abrió un período crítico de lucha de luces, matrimonio del fulgor y las sombras. La luminaria de los cinco fanales que adornaban la plaza contribuyó a facilitar las tareas de acoplamiento en el vehículo del interminable equipaje de tu mujer» (Gabriel y Galán, 1993:15). Es obvio que el cuadro contiene una alusión implícita al ambiente político y al propio espíritu de Pedro de Vergara (período crítico de lucha de luces), cuya conciencia se debate entre dicotomías y dudas de difícil resolución.

Por otra parte, la degradación del entorno se focaliza sobre un paisaje urbano sórdido, degradado por la miseria y la pobreza (que vuelve a repetirse más enconadamente en las páginas 213-215, con el episodio de los jumentos cargados de yeso y el acoso de los mendigos), pero también por la violencia, no solo del ejército francés, sino de los propios patriotas, que asaltan multitudinariamente a Vergara (Gabriel y Galán, 1993:242-244) y que terminarán con su vida. Todo ello incide de una forma particular en la percepción del bobo ilustrado, cuyo sentimiento de soledad parece estar en consonancia con el ambiente que lo rodea, según lo expresa él mismo en las primeras páginas de la novela, al contemplar la Plaza de los Mostenses (Gabriel y Galán, 1993:21).

La misma perspectiva de envilecimiento que aplica Pedro de Vergara sobre lo externo afecta al espacio interior de su propia casa (reflejo de su estado espiritual, como se ha argumentado antes [Bachelard, 2004:33-106]), aunque inmediatamente ese espacio va a ser vivido de distinto modo, merced a las posibilidades que le proporciona la soledad. Pedro de Vergara empieza a encontrar esa misma noche (la de la marcha de Isabel) su propio lugar y su propia individualidad; también, su propia vivencia del tiempo, su propia temporalidad, pese a que dicho espacio haya sido organizado (en última instancia) por una Isabel con ánimo inconsciente de despersonalización o (como el narrador afirma en el capítulo II) por estricto resentimiento personal (Gabriel y Galán, 1993:22). 


\section{EL MADRID SÓRDIDO}

El espacio novelesco de Madrid se postula como un territorio «desolado, polvoriento y desértico», tal «después de una batalla» (Gabriel y Galán, 1993:115), símil justamente en consonancia con el ambiente socio-político del momento. La atmósfera del cuadro descriptivo introductorio a la salida de Pedro de Vergara hacia la librería Fuentenebro (capítulo XIII) es comparable en cierto modo a la descrita al inicio de la novela, de tal manera que en contraposición a la agitación que impone el conflicto entre el ejército francés y los defensores patriotas, percibimos connotativamente una ciudad sin actividad alguna, inerte, sumida en el silencio (un silencio narrativo-ambiental, no histórico).

Otro ejemplo de espacio arquitectónico (que, aunque no esté relacionado exactamente con los estados anímicos del individuo - en este caso sería muy forzado justificar tal vínculo-, sí debe ser situado en una misma textura de percepción subjetiva) lo constituye la librería de Fuentenebro (Gabriel y Galán, 1993:116). Lo significativo del espacio interior del local lo configuran, en primer lugar, sus limitaciones volumétricas, su angostura; después, el hecho de que sea un espacio ocupado enteramente por numerosísimos y abigarrados volúmenes y por un mostrador exiguo; y, finalmente, por la heterogeneidad que, en cierto modo, impera en la reducida habitación. En este sentido, Vergara llega a referirse más abajo a este espacio peculiar como covacha (Gabriel y Galán, 1993:117).

En la misma línea de sordidez espiritual que se ha comentado, el capítulo XXIV se configura como una ansiosa búsqueda de Vergara por varias calles de un Madrid amenazante y desconocido, en busca de la casa de Francisco Rodríguez, en un intento obvio de deshacer el entuerto a que dio lugar la conversación entre ambos. El itinerario lo lleva a término en medio de un sentimiento creciente de miedo y de sensaciones subjetivas que reflejan la conmoción interior del individuo ante la amenaza (real o no) de la muerte; además, en este itinerario opera una sucesión de momentos climáticos, como el episodio de la recua de jumentos cargados de yeso (Gabriel y Galán, 1993:213) que terminan por envolver en polvo blanco y convertir en una caricatura de sí mismo a Vergara, o el acoso de los mendigos (Gabriel y Galán, 1993:215-216).

El trance de los burros cargados de yeso pone de relieve a un individuo cuya capacidad de ejecución y solvencia resolutiva están mermadas ${ }^{3}$, del mismo modo como su espíritu de bobo ilustrado lo mantiene en una actitud de cierta inercia con respecto al devenir histórico: «Irritado contra ti mismo por tu torpeza, escupiendo la película de yeso que secaba tus labios. No te atrevías a correr: hubiera sido echarte sobre las espaldas a todos los fantasmas de la ciudad encanallada (Gabriel y Galán, 1993:213). La ciudad, además, se torna un espacio de amenaza, a veces imprecisa, de sombras más que de individuos: «No era un peligro físico concreto, la muerte no se mostraba de manera perentoria, todo aquello se asemejaba a un gran desprendimiento y lo más angustioso era la inutilidad de intentar aferrarse a algo consistente» (Gabriel y Galán, 1993:212).

3 Simbólicamente, la peripecia muestra a un individuo rodeado de inconvenientes molestos que finalmente, incapaz de someterlos a su control, terminan por agredirlo, enmascararlo o enajenarlo. 
El itinerario de Vergara, preso del terror, hasta la casa de Francisco Rodríguez, nos presenta a un Madrid inmerso en olores fétidos y en un ambiente sórdido de menestralía y de vida cotidiana, que inciden de forma peyorativa en el bobo ilustrado y contribuyen a acrecentar su estado de pánico ante la posible inminencia de la muerte por un asalto de los patriotas (Gabriel y Galán, 1993:214). Su estado interior es paralelo al estado general de la ciudad, según él la percibe, si bien Vergara justifica ese estado como algo inherente a Madrid desde tiempos remotos. La contaminación microbiana del aire se extiende de igual modo, metafóricamente, al significado de la presencia del ejército francés, ejemplo de sometimiento y violencia, con el que Vergara no comulga, pese a sus tendencias afrancesadas. La alusión al ejército como elemento que aporta fetidez al ambiente justifica la idea de que el espacio novelesco adquiere significados connotativos de notable carga dramática (Gabriel y Galán, 1993:214).

El acoso de los mendigos que sufre Vergara en su itinerario (Gabriel y Galán, 1993:215216) es otro de los aspectos que conforman una visión desordenada no solo de la ciudad, sino también el propio estado espiritual del protagonista. La situación representaría, de nuevo, no solo un acoso físico sino un símbolo externo vinculado a la propia persecución moral o ideológica de la que se siente víctima. Es decir, el estado de conmoción interior mencionado más arriba queda somatizado en la relación que Vergara establece con el ambiente; el ambiente responde de forma sórdida o violenta porque también el espíritu de Vergara se halla en un estado similar. La relación entre los mendigos y el periodista se torna agónica, de tal modo que uno (el grupo más numeroso) parece que pretenda absorber al otro, contaminarlo o exterminarlo: «No te golpeaban, se diría que sus intenciones eran desgarrarte por completo las ropas, rozarse con tu piel infestándote hasta convertirte en un andrajoso como ellos» (Gabriel y Galán, 1993:215).

El clímax de depauperación iniciado por Vergara a la busca del domicilio de su compañero de redacción (Gabriel y Galán, 1993:218), afronta su último movimiento hacia el final del capítulo XXIV (Gabriel y Galán, 1993:217-219), cuando Vergara penetra en el barrio de las Injurias (cuyo nombre — es obvio - participa del espíritu y del devenir ontológico del bobo ilustrado). El ambiente de este nuevo espacio narrativo concierta semióticamente con los elementos perturbadores recién superados por el protagonista y, si cabe, incrementan su significado espiritual o simbólico en relación con el alma disminuida del bobo ilustrado. La suciedad, la fetidez del ámbito cerrado y su sordidez constituyen, nuevamente, signos somáticos que se condicen con el estado moral que atraviesa el protagonista. Especialmente, la mezcla de los distintos y — por lo general - desagradables olores logran transmitir una atmósfera de máxima pobreza y deterioro, que concluye con la imagen del cadáver colgado de Francisco Rodríguez y la nota que alude a la inexistencia de Rahel Levin (para las referencias históricas de esta intelectual judía, véase Arendt, 2000). El cadáver mismo es descrito descarnadamente por un protagonista desgarrado de sí y de su propio contexto (Gabriel y Galán, 1993:217-218).

La vinculación entre la situación socio-política y el espíritu de Vergara es más que evidente, a tenor de una serie de matices. En primer lugar, el icono del ya mencionado cadáver del perro en descomposición del arranque de la novela; en este sentido podemos establecer —en términos de similitud - que el espíritu del bobo ilustrado podría concentrarse expresivamente en el sintagma perro muerto y en descomposición. Ejemplo de ello es el propio comentario del periodista hacia el final del capítulo xxv, tras regresar a su casa después del hallazgo del cadáver de su compañero de redacción. Ha rechazado violentamente a Mariblanca y el universo ha adquirido connotaciones 
de derrota y de desencanto evidentes tras conocer la noticia de la inexistencia de Rahel: «Tu vida se había descompuesto en pocos días de manera vertiginosa. Como España, pensaste, y te volvió la basca a la garganta, quedándose todo en suspenso» (Gabriel y Galán, 1993:228).

Otros pasajes, cuantitativamente menos importantes y diseminados con cierta regularidad a lo largo de la narración, colaboran, no obstante, en ofrecer ese punto de vista afectado de sordidez que nos aporta el punto de vista de Pedro de Vergara. En el mismo sentido espiritual que se ha comentado para los aspectos precedentes, el personaje contempla, al dirigirse una mañana al periódico (Gabriel y Galán, 1993:45-46) el ajetreo callejero como a través de un cristal sucio (Gabriel y Galán, 1993:45). En el mismo trayecto matinal hacia la redacción, Vergara nos refiere un estado de ánimo poco constructivo que se proyecta sobre un espacio urbano hostil al caminante (Gabriel y Galán, 1993:45). En la tertulia, los comentarios sobre el pueblo de Madrid ponen de manifiesto la misma percepción del protagonista, esta vez en cuanto a la higiene: «El pueblo madrileño era esencialmente sucio, anárquico, y escudaba tal condición bajo el razonamiento de que las cosas de la higiene eran algo íntimo en lo que nadie debía entrometerse» (Gabriel y Galán, 1993:76); del mismo modo que ocurre algunas páginas más adelante (una vez que Vergara ha salido de la tertulia), en lo referente a los olores que flotan en el aire, o la basura esparcida por las calles (Gabriel y Galán, 1993:79). Estos dos últimos ejemplos (Gabriel y Galán, 1993:76, 79) se refieren a aspectos meramente físicos o ambientales, pero es indudable que contribuyen en el mismo sentido subjetivo de elaboración del entorno sórdido u hostil que percibe Vergara, no solo como algo exterior al individuo, sino como una instancia que se proyecta en su estado anímico y espiritual, y es al mismo tiempo reflejo de este.

\section{LA FIGURA DE RAHEL LEVIN O EL IDEAL FEMENINO: SENSUALIDAD Y DESEO, BELLEZA Y VERDAD}

En el contexto de un matrimonio inane, que queda en suspenso desde el momento de la partida de Isabel (no es desechable el matiz de la relación fónica entre Isabel y Rahel), Pedro de Vergara expande hasta el extremo sus impulsos sexuales (previsiblemente, si tenemos en cuenta que su asistencia a la tertulia viene de atrás, iniciados en la extranarración), aunque en un ámbito mental, o así parece ser (de ahí que califique de «lujuria desperdiciada» tales afanes, por tener su origen en estimulaciones de origen no físico). La necesidad $\longrightarrow$ la ejecución misma, mental o física - de expansión sexual (estimulada por imágenes mentales propicias a su imaginario) o sensual -incluso poética o intelectual, pues esas parecen ser también las raíces de sus visiones lujuriosas - promueve un incremento constante en el deseo de Vergara sobre la figura de Rahel Levin. Obviamente, Vergara juega ante sí mismo al estímulo intelectual provocado por el imaginario erótico que él mismo se ha fabricado de la intelectual judía, y nos presenta una mujer sumisa, silenciosa, cumplidora de sus intenciones y caprichos, de ahí que la Rahel imaginada, imaginaria, logre una pureza comparable a una canéfora o a una vestal rubeniana.

Aunque literato o poeta frustrado, la capacidad y el desvelo poéticos de Pedro de Vergara, es decir, su preocupación por la palabra escrita y por la palabra formulada en tanto que fuerza mágica, insuflada ya de un romanticismo incipiente, comparecen en tanto que forma - también- de planteamientos de seducción o de dominación sobre la figura de Rahel. De Paz (2003:204) considera que «En el primer romanticismo (igual que en el surrealismo) el artista 
como mago se concibe como alguien que, aunque aparentemente encante al mundo, en realidad lo desencanta, es decir, muestra que el mundo encadenado, el mundo como conjunto de relaciones entre hombres, el mundo del lenguaje, de los hábitos de la percepción y del comportamiento, debe ser liberado a través de un modo diferente de conocer y percibir». Digamos que las pulsiones eróticas de Pedro de Vergara se superponen a sus preocupaciones o a su identidad política, ambigua o cobarde. En realidad, el protagonista es un hombre incompleto, insatisfecho y en conflicto permanente entre la realidad y el deseo.

Pedro de Vergara proyecta la figura de Rahel Levin sobre la sirvienta María (Mariblanca, como él decide nombrarla), a quien le indica que se vista con las prendas de Isabel. De esta forma el periodista sincretiza sus pulsiones eróticas sirviéndose de una figura real (Mariblanca), más la sensualidad que le proporcionan las ropas (de la moda francesa) no usadas o abandonadas por Isabel, más la recreación imaginativa de la intelectual judía. En rigor, el desvelo erótico-amoroso de Pedro de Vergara se focaliza sobre Rahel como culmen o desideratum de un modelo femenino, sensual y amoroso, inalcanzable y adecuadamente promocionado por sus compañeros de tertulia.

Pero la imagen evocada y degradada de su propia mujer —-Isabel— subyace, primero, a la figura real de Mariblanca, con quien va a ser comparada; $y$, en segundo lugar, a la imagen idealizada de Rahel Levin. De tal modo, las tres mujeres contribuyen a la configuración del imaginario erótico-sensual de Pedro de Vergara mediante la superposición de rasgos de cada una de las tres figuras femeninas. Del plano evocado de Isabel, la imaginación de Pedro de Vergara se desliza en seguida al plano real de Mariblanca (presencia física que cataliza sus pulsiones) e inmediatamente la blancura de la piel de la muchacha y otras características más sutiles (Gabriel y Galán, 1993:40) lo trasladan a la evocación idealizada (en realidad, una forma de anhelo y deseo erótico) de la judía Rahel.

En el episodio del lavatorio de pies (Gabriel y Galán, 1993:39-44), de evidentes resonancias evangélicas, Mariblanca representa en el plano de la realidad (y también en el plano simbólico) una forma condensada del deseo de Pedro de Vergara con respecto a las carencias de su propia mujer ${ }^{4}$ y lo primero que le llama la atención es el color de la piel de la joven muchacha, que «Contrastaba con el color de carne asada de Isabel» (Gabriel y Galán, 1993:39). Este detalle parece, inmediatamente, hacer cambiar de opinión al bobo ilustrado sobre la orden que acaba de transmitir a la joven, como si íntimamente se censurara a sí mismo tal comparación, por desleal o por pecaminosa con respecto a su matrimonio: «A punto estuviste de decirle que se retirara, que te lavarías tú solo, pero afortunadamente estabas demasiado cansado» (Gabriel y Galán, 1993:39-40).

A partir de aquí, el lenguaje (junto con la acción en sí misma) se torna sugerentemente sensitivo; la actividad de la muchacha (que sustituye a la imagen de Isabel $^{5}$ en función de su sometimiento servil a la orden de Pedro de Vergara) sugiere desde el primer instante una

\footnotetext{
${ }^{4}$ Isabel es degradada en favor de Mariblanca en primera instancia, pero más aún con respecto a Rahel, quien la va a sustituir en todos los planos, como modelo intelectual y erótico quintaesenciado.

${ }^{5}$ La imagen que se nos transmite de Isabel se configura según el principio de sustracción o negación (degradante), mientras que las figuras de Mariblanca y Rahel Levin se conforman según el principio de adición o afirmación (constructivo, edificante, idealizador, creativo o estimulante).
} 
promesa de sensualidad que se cumple hasta donde lo permite el narrador-protagonista, y que se irá transformando en otras imágenes evocadoras más hondas para el mundo subjetivo del bobo ilustrado (Gabriel y Galán, 1993:40). Es decir, los rasgos físicos de Mariblanca señalan aquellos otros solamente atisbados e intuidos de la judía Rahel, cuyo origen es, en realidad, un estimulación imaginativa formada a partir de los comentarios que sobre esta mujer se transmiten en la tertulia a la que asiste Pedro de Vergara. La sensitividad erótica del hombre se activa, por tanto, por estimulación física (el tacto de las manos de la muchacha sobre los pies mojados del hombre), pero también gracias al parecido que se establece subjetivamente entre la sirvienta y la intelectual judía (Gabriel y Galán, 1993:40).

Mariblanca sirve simultáneamente de motivo erótico directo (mediante el acto del lavatorio) y de plano proyectivo de la figura de Rahel Levin. En cuanto a lo primero, la muchacha representa una transformación dentro del ámbito de liberación personal que se opera en Pedro de Vergara a partir de la ausencia de su mujer. En primer lugar, porque esta circunstancia permite que el sentido erótico del bobo ilustrado se despierte y se proyecte inmediatamente sobre Mariblanca, al hacerse consciente de los rasgos de la muchacha, que se resaltan de forma particular en relación con los de su propia mujer — hacia quien demuestra una indiferencia flagrante-, y que da lugar a que él también se preste a idéntico acto, cargado de indudable significación erótica y activado ya desde el momento en que los gestos y movimientos del simple lavado se transforman (al menos en la percepción sensual de Pedro de Vergara) en caricias que consiguen despertar la sensualidad del periodista: «Mariblanca había deshecho su moño y una inmensa cabellera castaña se abrió sobre su rostro pugnando por enturbiarle la mirada. Tomó uno de tus pies y empezó a secarlo con sus cabellos escurridizos» (Gabriel y Galán, 1993:41).

Más aún, los rasgos femeninos de la sirvienta muda (que Pedro de Vergara relaciona primero intuitivamente y después conscientemente con Rahel Levin) y sus propios gestos promueven en seguida la voluptuosidad del periodista, que la contempla sentado mientras ella se halla inclinada en el lavatorio (Gabriel y Galán, 1993:40).

En cuanto al plano proyectivo de Rahel Levin, los rasgos físicos de Mariblanca se superponen a los de aquella, a quien Pedro de Vergara previsiblemente conoce por retratos, además de por los comentarios vertidos en la tertulia de la botica. Las sutiles cualidades de la piel de Mariblanca, unidas a los gestos del lavatorio de pies, conforman una imagen plena de sensualismo y deleite para el bobo ilustrado que, finalmente, concluyen en una a modo de laxitud extática o estado de arrobamiento. De forma superpuesta, la presencia de Mariblanca (sobre todo en virtud de la sutileza de sus rasgos femeninos) consigue la perfecta estimulación sensorial en el periodista de la Gazeta para que en un ámbito estrictamente imaginario se materialice (mental, subconscientemente) Rahel Levin, objeto primordial del interés del periodista y motivo erótico-amoroso que contribuye a sus ensoñaciones y a sus despliegues poéticos o epistolares (Gabriel y Galán, 1993:39).

\section{EL INDIVIDUO Y LA FIGURA FEMENINA COMO FIJACIÓN ERÓTICA}

Pedro de Vergara obliga o solicita a Mariblanca que se vista con las prendas que Isabel tiene ocultas u olvidadas en un arcón. Esta transformación está cargada plenamente de ero- 
tismo. Mariblanca proporciona (a un nivel de realización subconsciente) el placer sustitutivo que Isabel nunca dio al bobo ilustrado la significación sensual, erótica, se dispara mediante la superposición de imágenes que pertenecen al universo sensual o sensitivo del bobo ilustrado, un hombre insatisfecho - en el fondo- en el plano sexual (y también creativo), ávido de modelos femeninos que colmen y amplíen el estrecho universo en el que se desarrolla su existencia.

Subyacente a esta entrega de indumentaria a la muda Mariblanca, permanece latente (constituye, en realidad, la única fijación del afrancesado madrileño) la figura de Rahel Levin. Inmediatamente, una vez que María se ha colocado las prendas de Isabel, Pedro de Vergara es invadido por la imagen de la judía (Gabriel y Galán, 1993:110). Es decir, el objetivo consciente de Pedro de Vergara desde que inicia el trasvase de prendas de Isabel a Mariblanca, es la conversión de la muchacha muda en motivo erótico proyectivo que sacie sus deseos fantasiosos o su mermada vida emocional de hombre solo dentro de un matrimonio insatisfactorio e inane, a la busca de la mujer ideal (en belleza e intelectualidad) que representa Rahel. Aparte de la proyección erótica a partir de las cualidades y gestos de Mariblanca, Pedro de Vergara transmite a la fámula un valor como mujer que hasta ese momento (y siempre según el punto de vista del hombre) ha permanecido asfixiado, muerto o «ciego», como él mismo añade. Desde su categoría servil, Mariblanca alcanza una dignidad sensual, o sensorial (paradójicamente a su condición de muda, en cierto sentido) distinta, adaptable al imaginario erótico del bobo ilustrado, aunque finalmente el temor de la muchacha haga malograr el desarrollo de su potencial femenino (Gabriel y Galán, 1993:110). Desde ese instante, una vez que Mariblanca es dignificada en el sentido más femenino, la metamorfosis inconsciente hacia la figura de Rahel Levin es un camino expedito. Inmediatamente, Pedro de Vergara sustituye el nombre de Mariblanca por el de Rahel y, por lo tanto, su percepción se dirigirá a ponderar las cualidades de esa figura femenina idealizada, en la que espíritu y materia (alma, mente y cuerpo) se imbrican y se nutren en una a modo de ósmosis mística.

Pero no solo el impulso erótico corporal —la visión o la recreación de su amada Rahel en la persona de Mariblanca - es lo que interesa a Pedro de Vergara. Una vez transformada en virtud del ropaje, Isabel-Mariblanca-Rahel (fusión femenina que contribuye al modelo quintaesenciado final) es la destinataria de la carta que el periodista afrancesado desea redactar en ese momento como fruto de la inspiración suscitada por el cuerpo de la sirvienta muda: «Voy a contarte de una vez el amor que nunca dejó de acusarme» (...) «Desde entonces, vivo para el amor» (...) «Como el silencio vive para la palabra» (...) «Si tú me has olvidado, yo diría que el tiempo no existe» (...) « ¿ Cómo vivir si cada olor y hora es un aniversario de tu estancia, si todas las palabras conducen a tu nombre?» (Gabriel y Galán, 1993:111-112).

Los fragmentos de la carta que escribe Vergara (Gabriel y Galán, 1993:104) tienen su origen en la estimulación erótica y visual que le proporciona Mariblanca, sometida a parecido efecto hipnótico (es decir, absorbida e identificada en cierto modo con la escena y el ambiente que espontáneamente ha organizado el periodista para su propio fin) que ella misma despierta en Pedro de Vergara. El periodista consigue alcanzar una visión placentera de Rahel Levin, que es lo que él busca en realidad desde el momento en que percibe sutilmente que los rasgos de Mariblanca son comparables a la imagen (probablemente contemplada en retratos que han llegado a él a través de miembros de la tertulia a la que asiste) de la intelectual judía. 
Mariblanca se transforma en Rahel a los ojos de Pedro de Vergara. Obviamente la mudez es invariable en la elaboración imaginaria de la judía. Paradójicamente, el desvelo verbal o poético de Pedro de Vergara está en desacuerdo con la condición de sordomuda de Rahel/ Mariblanca, de tal modo que el diálogo y la posible respuesta a sus cartas (concretamente a la carta que escribe simultáneamente a la visión que permanece frente a él) se anula, configurando de este modo un diálogo unidireccional que, en definitiva, sume al bobo ilustrado en una soledad en la que, verdaderamente, no existe el tú (becqueriano, saliniano) amoroso, sino una imagen que es una sombra desleída, de imposible capacidad receptiva. Ese invadeable obstáculo comunicativo parece llegar simbólicamente al paroxismo mediante la razonable reacción de Mariblanca/Rahel, atemorizada por la actitud de Pedro de Vergara que apresuradamente escribe sus pensamientos mientras la contempla, o bien por la incapacidad de soportar el nivel de significado (erótico, «satánico» si seguimos al bobo ilustrado) de la utilización de los ropajes de Isabel con fines poco habituales.

Y, por tanto, la carta y la visión, el carácter sensual del rito y la formulación poética de lo escrito simultáneamente se desmoronan; las palabras creadas por unos instantes en medio del dominio mágico pierden su semanticidad y su sentido (emocional, poético y lógico), y todo retorna a la misma inutilidad de otros intentos previos: «El mundo había cambiado, se te hacía irreconocible, ajeno y agresivo, y no debía pillarte fuera de tu casilla, al menos durante esa noche» (Gabriel y Galán, 1993:113).

El fracaso en el intento de elaboración poética a partir del rito-visión de Rahel Levin termina situándolo al margen del mundo, al menos contribuye a la alienación espiritual en tanto que (de nuevo) la realidad (el mundo) se configura en términos que se hallan a mucha distancia del deseo, y se vuelve — por ello mismo- «agresivo y ajeno» (Gabriel y Galán, 1993:112-114). Obviamente, la existencia de Pedro de Vergara está condicionada por la infravaloración que como hombre sufre en su matrimonio con Isabel, mujer que se encuentra muy lejos de cualquier referencia idealista deseada por Pedro de Vergara, que es consciente de que Rahel Levin representa, sobre todo, la utopía, tanto por el modelo de mujer (tan diferente de Isabel) como por la distancia geográfica en la que se halla (circunstancia que contribuye aún más a la idealización).

En este contexto de utopía emocional, la posible (e improbable) comunicación con Rahel Levin solo se materializa en unas cartas platónicas, escritas al vacío de la soledad del hombre, pese a que el individuo Pedro de Vergara ponga en ellas toda su fe y confíe, en el fondo, en el azar y en su propia libertad. Al mismo tiempo, Pedro de Vergara es consciente de la dificultad de que tales cartas arriben a su destinatario. Sabedor de esa utopía, lo relevante es la emoción que se despliega en el acto de la escritura, pese a que la posibilidad de la respuesta sea ínfima y remota, de ahí que el estilo de su escritura se acerque más a la poesía (aunque de hecho sea poesía) que a la prosa.

En efecto, el periodista utiliza las cartas dirigidas a Rahel como un motivo de excitación sensual o sexual; la escritura se vuelve materialidad en el sentido de que la imaginación de Pedro de Vergara imprime metafóricamente las palabras sobre la piel de Levin. Escritura y sensualidad (lujuria, afirma él mismo), por lo tanto, se imbrican en un sentido ontológico y redentor. La judía constituye, en definitiva, un fetiche literario, un objeto que Vergara utiliza imaginariamente a su antojo: la mujer (la imagen de la mujer, la idea perfecta del modelo 
femenino), puede ser sometida a «descabelladas garzonías» (Gabriel y Galán, 1993:105) y, como respuesta, obtendrá el silencio, la sumisión utópica del cuerpo amado (encarnado, esta vez, en el de Mariblanca, pero en rigor siempre fantaseado según los mecanismos de la sensualidad erótica del propio individuo).

Pero la existencia real de Rahel Levin es puesta en duda por Vergara desde el instante en que conoce la condición falsaria de su compañero de periódico Francisco Rodríguez Gallego, un supuesto patriota infiltrado al parecer en la Gazeta y que es quien actualiza al grupo de contertulios ciertos pormenores en torno a la judía. La incertidumbre de Vergara se manifiesta, entonces, con cierta agresividad sobre su compañero. El pasaje (Gabriel y Galán, 1993:211) nos revela qué grado alcanza el pathos del bobo ilustrado dentro de las relaciones de idolatría establecidas con respecto a Rahel.

La derrota del individuo (también la derrota física, el cansancio extremo) se revela como única conclusión del sórdido itinerario en busca de su compañero de redacción. Las sensaciones que se nos transmiten desde el punto de vista de Vergara, subrayan la degradación como corolario no solo de su peripecia por una zona determinada de la ciudad, sino como último término de una vida de insatisfacciones, pese a los momentos más o menos fugaces, más o menos duraderos, que le han proporcionado placer.

\section{LA IDENTIDAD POLIITICA: EL INDIVIDUO EN LA FRONTERA}

Desde el punto de vista político, Pedro de Vergara se debate en una dicotomía que lo implica moralmente: el apoyo al nuevo cambio de dinastía, con José Bonaparte como rey, o el rechazo a la invasión francesa. Esa aparente atonía ideológica queda justificada y demostrada en numerosos pasajes de la novela. Significativamente, y al modo como Dámaso Alonso escribiera sobre el Madrid de la posguerra en Hijos de la ira, para Pedro de Vergara «Madrid aparecía cercado por el fuego», donde el término fuego alberga la dilogía «calor sofocante» y «conflicto bélico», pese a que la afirmación siga desarrollándose en el sentido térmico o climático (Gabriel y Galán, 1993:23).

El personaje se sitúa — «insulso, carente de tesón y convicciones» (Gabriel y Galán, 1993:32) - en un punto de irresolución al admitir la validez política de cualquiera de las alternativas, pero adoptando una visión crítica con respecto a las vías de ejecución de cada una (Gabriel y Galán, 1993:34). La crítica de Pedro de Vergara sobre la sociedad española de principios del XIX, inmersa en el significativo contexto político, constituye uno de los rasgos de su identidad narrativa como individuo. Un rasgo que, del mismo modo que su infravaloración como ser humano o como hombre, aparece siempre con signos manifiestos de degradación. La mirada de Pedro de Vergara se extiende con desconfianza, impregnando los matices de la realidad circundante de una pátina léxica de escepticismo y de mezquindad, que del mismo modo lo afecta a él como elemento contemplativo y participador de los dominios que describe: «Los españoles se te aparecían en ese momento como jactanciosos, pródigos, flojonazos, displicentes y sobremanera vanos. Bastaba con pensar en los mirones y fisgadores, gentes cuyo oficio consistía en caer sobre los demás como arañas enredadoras. A aquellos rasgos se les pegaban otros más que los iban penetrando insensiblemente, apolillándolos y ensuciándolos sin remisión. Inane te sentías tú también, con la memoria enmarañada 
y la voluntad vacilante, características del Pedro de Vergara de siempre» (Gabriel y Galán, 1993:21). Esta situación da lugar, por tanto, a una duda continua (que contiene en sí el signo de la reflexión) y, finalmente, a la inacción (Gabriel y Galán, 1993:34).

Además, su postura política ambigua, indecisa o fronteriza, queda expuesta mediante su colaboración, aunque de forma clandestina (Gabriel y Galán, 1993:107), con El Correo del Otro Mundo, periódico del que, una vez ausente Isabel, encuentra un recorte de un artículo cuyo tema de fondo es — siguiendo la línea editorial — el patriotismo.

El artículo, firmado por «La buena Española» (acaso pseudónimo del propio Pedro de Vergara) defiende la idea de recibir al Monarca «con traje rigurosamente hecho a la española; porque así, a más de llenarnos de honor con la memoria que por él atraeremos, tal vez seremos tan afortunadas que inspiremos a todas nuestras compatriotas el deseo de seguirnos». El escrito, además, refiere la necesidad de la sencillez de tales prendas, cuyas telas deben ser asimismo españolas, y critica a quienes prefieren «la ignominia de parecer francesas a la gloria incomparable de ser honestas españolas» Con esto, concluye que el Monarca debe distinguir bien quiénes son verdaderamente españolas y quiénes «semi-españolas, peores en realidad que las extranjeras», condición que supone una «prostitución de la formalidad y decoro español» (Gabriel y Galán, 1993:108).

Si, como sutilmente parece indicarse, el artículo está escrito por el propio Pedro de Vergara, la idea de que el periodista permanece en una duda constante acerca de sus tendencias o intereses políticos, entre el apoyo a la patria y la decantación por la instauración del rey José Bonaparte, el artículo encontrado demuestra a las claras que sus simpatías patrióticas existen, pero se ocultan prudentemente detrás del falso marbete de «La buena Española», subrayando así la ambigüedad de su pensamiento político (Gabriel y Galán, 1993:108-109).

Al inicio del capítulo XIII (Gabriel y Galán, 1993:117), cuando se dispone a visitar la librería Fuentenebro, él mismo se califica de «bicho raro» por el hecho de no respetar la hora de la siesta (tal y como culturalmente corresponde al ámbito hispánico). Obviamente, tal rasgo debe extenderse de la misma forma a su ambigüedad política, a su voluntad de mantenerse en un punto indeterminado en medio de las dos tendencias por las que se decanta la sociedad madrileña (o española) en aquella hora histórica. En este caso en particular, Pedro de Vergara asiste a la librería en la que se edita clandestinamente el periódico patriótico El Correo del Otro Mundo, e incluso se ve obligado a representar el papel de Antonio Pérez. El bobo ilustrado declara que el cónclave de contertulios en la librería Fuentenebro corresponde a una «cita patriótica semanal» (Gabriel y Galán, 1993:115), por tanto sus simpatías políticas mantienen un punto de apoyo evidente en esta alternativa. A esto se suma la noticia de la detención de su tío, José Victoriano Gallardo, a quien el bobo ilustrado reconoce para sí haberlo «abandonado a su suerte» (Gabriel y Galán, 1993:117). Tal gesto — por otra parterevela una falta de implicación hacia su propio tío, por miedo, por desinterés político o por la mencionada atonía ideológica de que se adolece el periodista.

Pero la ambigüedad política Pero Pedro de Vergara no deja de dar sus avisos ni de mostrar que las dos alternativas posibles en el camino histórico de España son compatibles en su espíritu. En seguida, el bobo ilustrado aporta una nota (Gabriel y Galán, 1993:118) que contesta o glosa a aquella otra carta hallada en el arca donde Isabel guardaba su ropaje fran- 
cés (Gabriel y Galán, 1993:108-109), en la que la autora (o el autor) defendía la necesidad de que las españolas vistiesen según ordenaba la arraigada tradición hispánica. En este caso, la tendencia afrancesada del bobo ilustrado se advierte al hacer notar que en ningún sentido se había usado ni establecido tal indumentaria tradicional, ni por «nuestro soberano Fernando VII» ni por «sus gloriosos ascendientes» (Gabriel y Galán, 1993:118). Está claro que, como sostiene el canónigo Arratia, de la nota «se desprendía un tufillo afrancesado, involuntario sin duda, peligroso en las horas actuales» (Gabriel y Galán, 1993:118).

El asunto de los vestidos femeninos contiene en sí los elementos apropiados para la exposición del conflicto ideológico subyacente: el enfrentamiento entre patriotismo y afrancesamiento, o entre tradición y progresismo, tal y como queda explícito en el diálogo entre el canónigo Arratia y el bobo ilustrado (Gabriel y Galán, 1993:119). No obstante, lo más significativo del encuentro entre el canónigo y Pedro de Vergara es la reflexión de este último en torno a las posiciones ideológicas. Para el bobo ilustrado (y en este sentido debemos recordar las palabras que Gabriel y Galán expone en el prólogo a la novela), todas las posturas son válidas en el sentido de que todas pueden ser convincentes desde cierto punto de vista; por tanto la capacidad del periodista para el dogmatismo — como el propio autor de la novela concluye en el prólogo_ es nula (Gabriel y Galán, 1993:119).

El espíritu de la perspectiva política es, además, representado en la tertulia mediante técnicas teatrales. Los tres miembros de reunión (Valgamediós, el propio Pedro de Vergara y Arratia) dan vida en un breve monólogo a tres personajes de la historia de España —el Gran Capitán, Antonio Pérez y el cardenal Ximénez de Cisneros-, que encarnan diferentes instancias de la historia de España. Lo significativo de este aspecto viene dado por la visión que ofrece el propio bobo ilustrado al encarnar el papel de Antonio Pérez (cuya personalidad resulta —en realidad - una mera excusa formal sin excesiva relación con el contenido del monólogo). Pedro de Vergara — el que nos interesa como individuo — se decanta, esta vez, por el patriotismo más definido, al exponer su desacuerdo con la violencia (primer aspecto del conflicto histórico del momento, sobre todo por las acciones del ejército francés) y con la política de Napoleón y defiende, además, el valor de España en cuanto a su posición frente a las demás naciones de Europa (aunque el estilo del personaje encarnado es difuso, debe entenderse aquí que el sentido de sus palabras se refiere al campo científico y humanístico) (Gabriel y Galán, 1993:122).

No obstante aún, Pedro de Vergara comenta, en la misma línea de su doble personalidad política, algún aspecto relacionado con la caricatura que Francisco Valgamediós ofrece de José Bonaparte (Gabriel y Galán, 1993:124). En su fuero interno, Vergara sabe de la falsedad que contienen las palabras de su contertulio y aclara que: «José no tenía nada del espantajo que pintaban las letrillas populares; era más bien agraciado de rostro y no tenía joroba alguna; tampoco era particularmente aficionado a la bebida» (Gabriel y Galán, 1993:124). Esta aseveración del bobo ilustrado se suma a su postura política neutral, o más bien habría que decir a su carácter de hombre razonable, que sabe ponderar equilibradamente los distintos aspectos de cada una de las dos «bandas» en que quedó dividido el país, patriotas y afrancesados. Pedro de Vergara es consciente de su ambigüedad ideológica y de su cómoda inercia política.

Tanto para los patriotas como para los afrancesados dispone de una visión crítica, sin duda poco constructiva, que le permite señalar los errores morales de ambos bandos. Al mis- 
mo tiempo, la percepción de sí mismo es conscientemente negativa, y sabe que su postura es siempre de «espectador pasivo, agrio y perezoso» (Gabriel y Galán, 1993:128), una postura que lo hace desconfiar de todos y, además, condescender con todos, «renunciando y afirmando por doquier» (Gabriel y Galán, 1993:128). De tal modo, la percepción de la realidad social y política y de su propia situación en el mundo resulta desalentadora, mezquina, como afirmará en el capítulo XIV refiriéndose al teatro en Madrid (Gabriel y Galán, 1993:128).

Toda esa inercia y su negativa a situarse en bando alguno siguen manifestándose en su visita al actor Claudio Bonoldi (Gabriel y Galán, 1993:134). Lo interesante aquí es, de nuevo, la negativa de Pedro de Vergara a que lo califiquen o lo sitúen entre los patriotas, como el propio Bonoldi considera, a raíz de la entrega de la carta. Las palabras (y los pensamientos) del bobo ilustrado son elocuentes en lo concerniente a su valoración de quienes rechazan al nuevo Rey: «Se guardó la bendita carta y tú pensaste con alivio: «Que os aproveche», como si te sintieras obligado a mantener una cierta distancia con respecto a ellos. «Y espero que sea lo último que se me pide» (Gabriel y Galán, 1993:135). E inmediatamente Pedro de Vergara sentencia —en el sentido ya comentado— sobre su posición ideológica, haciendo valer su ambigüedad y su pensamiento político fronterizo (Gabriel y Galán, 1993:135).

En la conversación con el actor en el Café de Oriente salen a relucir de nuevo - en breves referencias- las posiciones políticas. Esta vez Pedro de Vergara defiende la presencia de los franceses por su posible influencia en la mejora de la calidad del teatro, postura que no es compartida, obviamente, por el actor. La atonía y la doble personalidad políticas del bobo ilustrado revelan, en el fondo, una defensa de la paz en sus diversos matices. El significado denotativo del término paz incluye varias acepciones que, en realidad, están contenidas en el sentido connotativo (ambiguo) de la expresión empleada por Pedro de Vergara, «vivir para la paz», y que implican al propio espíritu del bobo ilustrado (es decir a su inercia política, ya comentada). En su acepción séptima, paz es «Genio pacífico, sosegado y apacible» (D.R.A.E.: http://lema.rae.es/drae/?val=paz), definición de perfecta medida para el espíritu del bobo ilustrado, quien previsiblemente concibe esta idea como una aceptación de la invasión francesa sin oposición patriótica. En otro sentido, la utilización del término remite a Vergara inmediatamente a la imagen de Rahel Levin, evocada como una figura real que proporciona la quietud o armonía espiritual y amorosa que, en el fondo, busca el periodista: «Para ti la paz era Rahel Levin, aunque nadie pudiese comprenderlo, ni siquiera tus compañeros de la tertulia de don Julián, para los que sin duda la divina no era más que un personaje literario, es decir, un motivo de especulación» (Gabriel y Galán, 1993:137).

Pero su miedo y su proposición de mantenerse constantemente a distancia del conflicto lo hace situarse también al margen de discusiones sensibles, incluso con el actor Bonaldi, puesto que entre el miedo y la atonía ideológica se halla la desconfianza en cualquier individuo (Gabriel y Galán, 1993:137).

El espíritu afrancesado de Pedro de Vergara (avalado por la evidencia de que la Gazeta es un periódico de claro apoyo el rey francés) no deja de suscitar en Bonoldi — quien lo califica de «afrancesado imaginario»- dudas sobre la consistencia real de la tendencia política del periodista (Gabriel y Galán, 1993:138). En contrapartida, Vergara desliza inmediatamente un comentario comprometedor como contestación a los datos que da Bonoldi acerca de la violencia del ejército francés (Gabriel y Galán, 1993:138). 
La autoestima de Pedro de Vergara es otro aspecto de interés. Ya en la despedida de su mujer, en el capítulo primero, se percibe cierto sometimiento al carácter femenino (de hecho, el periodista permite que Isabel se marche a Andalucía, admitiendo los argumentos paternos). En la noche que pasa con la actriz, mientras suben a la anciana hasta el tercer piso, su autoestima vuelve a ponerse de relieve: «Y allí te quedaste tú de pie, húmedo, vacilante, con una sensación de estulticia íntima que sin duda se reflejaba en tu rostro» (Gabriel y Galán, 1993:145).

La visión de sí mismo, de su vida y de su entorno (también del otro) se propone — cuando menos - como incompleta, deficitaria, casi caricaturesca a veces o esperpéntica en el sentido más valleinclanesco (Gabriel y Galán, 1993:45). Pero, también, como vivida dentro de una irrealidad onírica, siempre sórdida, que perturba su serena medianía (Gabriel y Galán, 1993:145).

Ante la creencia de la entrada inminente de las tropas de Castaños, la perspectiva de Vergara con respecto a su trabajo en el periódico y su propia vida se torna pesimista (Gabriel y Galán, 1993:202). En este sentido, el temor a un posible fin le lleva a reflexionar sobre la identidad histórica de los afrancesados, una cuestión que, en el fondo, no deja de reducirse a la mera adjetivación. De nueo, la perspectiva ideológica de Vergara se sitúa en una región fronteriza (rechaza la violencia del ejército francés, pero es partidario del reinado del rey José), que sopesa la circunstancia histórica con el único objetivo de salvar a la nación o lo que en esos momentos quedaba de ella (Gabriel y Galán, 1993:202).

Pero la crítica a los patriotas subyace a toda esa duda, contra la que ni siquiera sirve el testimonio del alcalde y el párroco del pueblo madrileño de Benturada (Venturada), quienes hacen llegar a la Gazeta una carta en la que describen con detalle las acciones violentas del ejército francés. La crítica se endurece especialmente al referirse al párroco, que «solicitaba una colocación decente para su persona»: «Esto fue casi lo que más te indignó: el cura preocupado sobre todo por su curato. Todo en la nación abocaba a la náusea, miraras por donde miraras» (Gabriel y Galán, 1993:204).

Además de que se plantea el sentido de la inclusión de la carta (un «canto jeremíaco», [Gabriel y Galán, 1993:204]) en el periódico, habida cuenta de que tales hechos eran extensibles, en realidad, a otra gran parte de la población. Lo que critica aquí Vergara es que, frente a la cara más destructiva y violenta del conflicto, el pueblo madrileño aprovecha las diversiones que el rey José sufraga con la intención de aplacar las posibles reacciones (como la del plan del atentado) contra su Corte (Gabriel y Galán, 1993:204).

En el mismo itinerario, Vergara — una vez que se ha zafado de los mendigos - reflexiona sobre su propia identidad socio-política y su identidad personal. De tal modo, el bobo ilustrado no se identifica, en realidad, con ninguna tendencia política (siempre entre dos aguas, se siente servidor de unos y otros, sin fidelidades incondicionales); al contrario, reivindica su carácter irresoluto y su naturaleza inofensiva y pusilánime ante cualquier circunstancia (Gabriel y Galán, 1993:217).

El carácter indeciso y laxo de Vergara se percibe también en el capítulo XXV, una vez vuelve a casa tras la busca y el hallazgo de su compañero suicidado Francisco Rodríguez, cuando reflexiona - tras rechazar a Mariblanca - sobre el plan de atentado a José Bonaparte: «Nadie tenía razón, como siempre. Y menos aún en el marco de una vida como la tuya, que 
hasta ahora había pendido como un leve hilo de seda, fláccido y oscilante por falta de tensión» (Gabriel y Galán, 1993:224).

$\mathrm{Su}$ afrancesamiento se deja traslucir en los comentarios que le dedica a José Bonaparte. En el capítulo XXV, en tanto reflexiona sobre el plan de atentado previsto por los patriotas, Vergara sostiene que Ese hombre no merecía una muerte tan ignominiosa, no merecía muerte alguna: era joven, apuesto y deseoso de pacificar (Gabriel y Galán, 1993:224).

De tal modo, su condición fronteriza se agrava en el momento en que el atentado a José Bonaparte se acerca y Vergara se halla frente a la posible alternativa de huir, aunque la preocupación por su tío lo sitúa de nuevo en una disyuntiva que es incapaz de resolver: «Tus enemigos resultaban cordiales amigos y tus amigos cordiales enemigos. (...) Y bien, eras un cobarde. Nada nuevo, todo el mundo es cobarde si no tiene otro remedio, sobre todo si la muerte le acecha como consecuencia de la ingenuidad, del atolondramiento» (Gabriel y Galán, 1993:225).

\section{CONCLUSIONES}

Partiendo de concepciones en torno al individuo narrativo mencionadas en la primera parte del presente trabajo, en el sentido de que «la falta de armonía entre la realidad y el héroe, que quisiera poseer un mundo de pasiones afirmativas y se encuentra en perpetua agonía en otro precario y deficiente» (Villanueva, 1979:44), o del sentido y el valor de la conciencia del individuo con respecto al mundo, es decir: «Que la conciencia quiera imponerse al mundo, que renuncie a ello, o que de alguna manera llegue a armonizar con el mundo» (Sobejano, 2003:46), y de los tres tipos de novela a que esta idea da lugar: «Del idealismo abstracto (Don Quijote), del romanticismo de la desilusión (La educación sentimental) y de aprendizaje (Wilhem Meister)»; esto es: «Ilusión, desilusión, conciliación» (Sobejano, 2003:46), estamos en condiciones de considerar que Pedro de Vergara se halla taxativamente en el segundo, en el del romanticismo de la desilusión (Vergara, él mismo lo comenta, es un romántico [Gabriel y Galán, 1993:193]), puesto que, en efecto, el ámbito que lo rodea se erige como territorio agónico, inarmónico, precisamente por esa contienda entre la armonía (el deseo) y la realidad.

De una parte, Vergara discurre en mitad de una ciudad sórdida e imbuida de un conflicto político y bélico. El espíritu del periodista se identifica y se traslada al cronotopo urbano, en el cual el cadáver cercano del perro permanecerá como un signo identificativo, además de premonitorio. Vergara es, en el fondo, un ser en soledad, y esa soledad ya está también en la ciudad y en el desajustado ambiente político, pues sus relaciones, menos que sociales, menos que vinculadas a individuos de su mismo pensamiento (afrancesados), permanecen en un limitado y estrecho círculo, en el que se insertan Mariblanca y Pepa Montserrat, mujeres que alimentan sus pulsiones sexuales y eróticas inmediatas, y que a la postre, forman parte - en silencio, hipócritamente - de la comunidad enemiga; además de Rahel Levin, elevada a la esfera de lo idealizado.

La ciudad es sórdida porque también es hostil, y así se demuestra en el itinerario que efectúa Vergara a la busca del domicilio de su compañero de redacción Francisco Rodríguez, a quien hallará finalmente ahorcado, víctima del terror. Madrid es una ciudad plena de olores fétidos, y una ciudad también que amenaza la vida del periodista de forma constante, 
contrarrestando ese anhelo de armonía que, en rigor, quiere encontrar en las tres mujeres mencionadas, a distintos niveles.

De otro lado, el acoso de los mendigos que sufre en ese itinerario mencionado, o la conmoción que le inflige el polvo de yeso de una carga de jumentos en la calle, en el mismo trayecto, revelan a un ser con poca capacidad para su propia defensa, a la vez que patético, desubicado, apartado de todo lo que signifique armonía. Además, su condición política de partidario de José Bonaparte lo sitúa, igualmente, en un estado de incesante vigilancia y temor. El clima político constituye, para Vergara, un factor de desasosiego, de enajenación y alienación; Vergara es un ser desasistido, disminuido por el ambiente, pero también porque su espíritu es un espíritu de bobo, es decir: candoroso en demasía, indeciso, laxo, un individuo en la frontera, como se ha comentado, puesto que no posee la capacidad de decantarse hacia ninguna parte.

Más aún, las mujeres a las que ama o admira, representan una parte personal e íntima que se expande una vez que su mujer y su hijo se han marchado a Andalucía. Es un hombre, por tanto, un ser, de doble concepción o de doble conciencia, pleno de impulsos inconfesables, entregado a su propia fantasía erótica; e incompleto, en definitiva, por ello mismo. Solo en la mujer, particularmente en su relación con Mariblanca, parece encontrar una armonía fantasiosa, una armonía que inmediatamente queda vinculada, por mímesis física, a otra mujer, la ideal, la que encierra todo un desideratum de virtudes, Rahel Levin.

Siguiendo el argumento de Sobejano mencionado arriba, Vergara es un ser, un individuo que, incapaz de imponerse al mundo, es arrastrado por las circunstancias que imperan en ese mundo. La realidad es, para Vergara, adversidad, y el héroe no es héroe, sino un hombre arrastrado en su conciencia por la ausencia de una energía suficiente, que cae no en la afirmación, o al menos no en una afirmación suficientemente pujante, sino inerte, cómoda; por tanto su agonía es una lucha de antemano perdida en medio de la precariedad del mundo que no quiere o no puede afrontar.

\section{REFERENCIAS BIBLIOGRÁFICAS}

Arendt, Hannah (2000): Rahel Varnhagen. Vida de una mujer judía. Barcelona: Lumen.

BaChelard, Gaston (2004): La poética del espacio. Madrid: FCE.

Chevalier, Jean y Alain Gheerbrant (2007): Diccionario de los símbolos. Barcelona: Herder.

De Paz, Alfredo (2003): La revolución romántica. Poéticas, estéticas, ideologías. Madrid: Tecnos-Alianza.

Gabriel y Galán, José Antonio (1990): «Retrato del escritor que se juega la vida». Cursos de verano. El Escorial, 1989, 69-83. Madrid: Universidad Complutense.

- (1993): El bobo ilustrado. Madrid: Alfaguara.

Gurméndez, Carlos (1989): El secreto de la alienación y de la desalienación humana. Barcelona: Anthropos.

LukÁcs, Georg (1971): Teoría de la novela. Barcelona: Edhasa.

Pena, M. ${ }^{a}$ Del Carmen (1998): Pintura de paisaje e ideología: la generación del 98. Madrid: Taurus. Sobejano, Gonzalo (2003): Novela española contemporánea: 1940-1995. Madrid: Mare Nostrum. Villanueva, Darío (1979): «La novela», en El año cultural 1979. Madrid: Castalia. 